\title{
Objetos domésticos e sua dinâmica afetiva em narrativas portuguesas contemporaneas
}

\author{
Household objects and their affective dynamics \\ in contemporary portuguese narratives
}

Denis Leandro Francisco

Hankuk University of Foreign Studies (HUFS) - República da Coreia

DOI: http://dx.doi.org/10.5902/2176148531646

Resumo: Este artigo analisa a dinâmica afetiva dos objetos domésticos em diferentes narrativas do escritor português contemporâneo António Lobo Antunes, a partir de algumas das formulações de Deleuze e Guattari sobre "liso" e "estriado", de Abraham Moles sobre o "kitsch" e de Jean Baudrillard sobre o "sistema dos objetos". A análise das obras literárias (Que farei quando tudo arde?, Exortação aos crocodilos, o meu nome é legião, Eu hei-de amar uma pedra e Que cavalos são aqueles que fazem sombra no mar?) indica que, na insuficiência ou ausência de afeto humano, esses objetos domésticos, ora convertidos em "objetos de estima", ocupam nessas ficções o lugar desse outro ausente que nunca responde às demandas afetivas e de atenção das personagens.

Palavras-chave: Objetos domésticos. Afetividade. António Lobo Antunes. Literatura portuguesa.

Abstract: This article analyzes the affective dynamics of household objects in different narratives of the contemporary Portuguese writer António Lobo Antunes, based on some of Deleuze and Guattari's formulations on "smooth" and "striated", some formulations by Abraham Moles on "kitsch" also on Jean Baudrillard's considerations on "system of objects". The analysis carried out on five of Lobo Antunes' literary works (What can I do when everything's on fire?, Exhortation to crocodiles, My name is legion, I have to love a stone and What are those horses that make shadow at sea?) indicates that, in the insufficiency or absence of human affection, these objects, once converted in "objects of esteem", occupy in these fictions the place of that absent other that never responds to the character's demands of affection and attention.

Key-words: Household objects. Affectivity. António Lobo Antunes. Portuguese Literature. 
Sem dúvida os objetos desempenham um papel regulador na vida cotidiana, neles são abolidas muitas neuroses, anuladas muitas tensões e aflições, é isto que lhes dá uma "alma", é isto o que os torna "nossos". (Jean Baudrillard. 0 sistema dos objetos, p. 98).

Objetos inanimados, tendes pois uma alma.

(Abraham Antoine Moles. 0 kitsch: a arte da felicidade, p. 22).

Denis Leandro

Francisco

\section{Introdução}

Deleuze e Guattari, em suas formulações sobre espaço "liso" e espaço “estriado", mostram principalmente que os espaços não têm todos a mesma natureza, e que esses dois espaços, na verdade, "só existem de fato graças às misturas entre si" (DELEUZE; GUATTARI, 1997, p. 180). Qualquer oposição simplista entre eles esconde as diferenças complexas que os caracterizam: o espaço liso estaria para a ausência ou para a multiplicidade das formas (espaço amorfo) assim como o espaço estriado estaria para a organização, para o mapeamento das coordenadas que o constituem. Percebe-se que o liso e o estriado engendram complicações e superposições muito mais complexas que qualquer dicotomia pode prever, já que esses espaços "colocam em jogo movimentos dissimétricos" (DELEUZE; GUATTARI, 1997, p. 189) nos quais as contaminações várias não permitem classificações estanques e compartimentadas dos espaços em "necessariamente lisos" ou "necessariamente estriados". o liso é "um espaço de afectos, mais do que de propriedades" (DELEUZE; GUATTARI, 1997, p. 185), e é como espaço de afetos, sobretudo no sentido que Freud dá a esse termo, que as casas figuradas nas narrativas do escritor português contemporâneo António Lobo Antunes se comportam: Freud utiliza o termo afeto para se referir à quantidade de energia das pulsões e das suas variações e, para ele, os afetos seriam reproduções de antigos acontecimentos de importância vital para o sujeito.

\section{Espaços de afeto}

As narrativas antunianas operam a partir dessa lógica espacial que reúne significações díspares ou propõe contaminações de um espaço em outro. Em Lobo Antunes, a casa atual mostra-se, com frequência, esvaziada e desinteressante, e os sujeitos ficcionais passam a habitar, ima- 
ginariamente, o espaço recheado de ornatos e de enfeites da casa passada, evidenciando a inegável permanência residual desses espaços de interioridade. Gaston Bachelard concorda que "as diversas moradas de nossa vida se interpenetram" (BACHELARD, 1993, p. 25) mas, enquanto para ele essa contaminação é sempre harmônica e os elementos contaminantes são sempre descritos como relíquias, "tesouros dos dias antigos", na ficção antuniana essa contaminação pode tanto operar a partir de elementos de significação destrutiva (como a doença que corrói o corpo e a casa de muitos de seus protagonistas) como de elementos se dignificação afirmativa:

Objetos

domésticos e sua dinâmica afetiva em narrativas portuguesas contemporâneas

As duas casas habitadas por essa personagem de Que farei quando tudo arde? coexistem num mesmo espaço-tempo de simultaneidades. 0 espaço do passado é reatualizado pela memória desse sujeito habitante que está em uma $e$ em outra casa - ou entre uma e outra, já que não pode decidir-se por nenhuma. Essa casa ficcional - repleta de cômodos e móveis atulhados de pequenos bibelôs, de enfeites de porcelana, de forros e cortinas de naperon - esboça um quadro do kitsch como uma das tendências da "cosmicidade" ficcional antuniana, essa "cosmicidade" que, diferentemente daquela proposta por Bachelard, manifesta-se nas cadeiras de plástico descartáveis, nos bibelôs quebrados e insistentemente colados, nos móveis e eletrodomésticos estragados e repetidamente reparados.

Entre uma e outra casa - ou em ambas simultaneamente - está também Celina, uma das quatro mulheres protagonistas de Exortação aos crocodilos. O elemento que indicia essa contaminação espacial é um "Rato Mickey" de pelúcia que a personagem ganhara do tio a quem idolatrava e que, sem explicações, abandona a casa da família.

1 Nota do revisor: a autora (ou autor) do artigo transcreveu as citações de Lobo Antunes exatamente como aparecem no livro, com quebras de linha e parágrafos. Por acreditar que seja relevante para a análise, decidiu-se não alterar os fragmentos, bem como não colocá-los com a margem de $4 \mathrm{~cm}$, como recomendado pela revista. 
Esse elemento ambivalente concentra significações afirmativas (a memória de momentos felizes passados com o tio durante a infância) e disfóricas (o repentino abandono do tio, o casamento a que Celina fora "induzida"):

Denis Leandro

Francisco

e era primeiro o cheiro da água-de-colônia e depois o meu tio sentado na borda do lençol com uma embalagem de cartão cheia de bichos-da-seda, a fazer-me sinal para que não falasse - Boa noite

a acordar os bonecos da prateleira, a trazer o Rato Mickey zarolho, a esfregar o focinho dele no meu nariz, a minha avó lavava a louça na cozinha a calcular pelo barulho das caçarolas, dos talheres, a minha mãe discutia com o meu pai batendo armários, o vizinho do segundo andar tocava vassouradas de protesto no teto, o meu tio escondia-se atrás do Rato Mickey e era o rato Mickey que falava comigo, não ele, o meu marido espantado de não notar ninguém na sala - Com quem estavas a conversar Celina?

[...] tornava a instalar os ursos e as tartarugas na prateleira, esfregava o focinho do Rato Mickey no meu nariz (o olho que era botão de colete percebia-se melhor que o outro)

colocava-o no travesseiro ao meu lado para me ajudar a atravessar a noite, por exemplo aqueles sonhos de quando vem um gatuno atrás de nós, todos fogem, tentamos correr e as solas prendem-se ao chão, ou quando um desconhecido nos rouba de casa e os nossos pais a assistirem sem nos defenderem nem nada, em certas alturas acordava sem motivo faróis de automóveis iluminavam o teto, notava-se mais ou menos a colcha e o tampo da cômoda, os automóveis desvanesciam-se no cruzamento, a colcha e a cômoda evaporavam-se, antes que os gatunos chegassem estendia a mão para o lado, agarrava o Rato Mickey, esfregava o nariz no focinho dele, o meu marido a empurrar-me estremunhado

- Larga-me não cheirava a feltro e a serradura, não me espiava com a pupila de madrepérola do colete, agrupava-se a resmungar no 


\author{
canto oposto da cama, sacudindo-me os dedos como um pato \\ se sacode na água, aquietava-se a protestar num ronco lama- \\ cento \\ - Já tomei o comprimido caramba \\ eu a acender o abajur no receio de adormecer derivado \\ aos gatunos, surpreendendo-me da ausência do meu tio e dos \\ bonecos na prateleira, de ser crescida, das minhas unhas pin- \\ tadas, a erguer-me, a encontrar no espelho do lavatório vin- \\ cos de expressão sobre a minha cara de criança (ANTUNES, \\ 2001a, p. 67-68).
}

Já adulta e vivendo com o marido em uma casa diferente daquela em que passara a infância, Celina arrasta para esse "novo" espaço o Rato Mickey da casa "antiga" e, mais que isso, repete a relação de "companheirismo" que havia entre ela e o objeto infantil, reproduzindo o diálogo impossível de antes e provocando o espanto do marido. Veja-se como passado e presente, infância e maturidade, casa de antes e casa atual se imiscuem de tal forma nessa narração que esses pares se tornam um só elemento, amalgamados pelo Rato Mickey enxovalhado e algo kitsch de Celina.

\section{Objetos de afeto}

Em Que farei quando tudo arde? há uma série de objetos significativos pela dinâmica afetiva que movimentam nessa narrativa: um anão da Branca de Neve sobre a geladeira, uma boia de plástico em forma de girafa, um par de bonecos de parafina daqueles que se usam para representar os noivos em bolos de casamento. Enquanto rememoram suas existências solitárias, seu dia-a-dia de perdas e de desencontros, os sujeitos antunianos revelam ao leitor seus espaços mais íntimos e, neles, deixam entrever seus objetos mais particulares: cartas cuidadosamente guardadas em gavetas, velhas fotografias imobilizadas sobre mesas de cabeceira, brinquedos de plástico largados em piscinas, miniaturas de noivos esquecidas em caixas de sapatos, forros de naperon, bijuterias.

Muitos desses objetos apresentam um traço kitsch que, por sua vez, incorpora em si um índice de depauperação: uma certa porção kitsch acompanha sempre o esboroamento - seja dos objetos, dos espaços ou dos sujeitos -, aproximando uma certa deterioração "subjetiva" à que se dá também nos objetos inanimados. O kitsch - que, por definição,
Objetos

domésticos e sua dinâmica afetiva em narrativas portuguesas contemporâneas 
Denis Leandro

Francisco

é o excesso, a inadequação, o exagero - esvazia-se na textualidade antuniana e passa a funcionar como mais um índice do desajuste sob o qual as personagens estão irremediavelmente inscritas.

Em uma das casas que atravessam esse espaço-tempo da infância da personagem Paulo, há um objeto significativo que, de algum modo, preserva esse espaço-tempo para sempre perdido e, simultaneamente, traz consigo as marcas de seu esfacelamento: um anão de jardim da Branca de Neve que seu pai comprara no Natal e que repousa, solenemente, sobre a geladeira. Esse objeto - tão imediata e facilmente classificado por todos como kitsch devido ao seu aspecto decorativo-imitativo - paira na memória de Paulo como um signo de sua antiga casa no Bico da Areia, espaço da saudade e da convivência - não importa se feliz ou se nem tanto - com os pais, sobretudo com o pai que, àquela altura, chamava-se ainda Carlos: "e quem diz o anão da Branca de Neve diz o tempo em que morávamos do outro lado do rio" (ANTUNES, 2001b, p. 382). Esse pequeno objeto, a exemplo de tantos outros que povoam os textos antunianos, funciona como um índice dessa "presença do passado no presente" (GAGNEBIN. 1994, p. 15), é essa presença-ausência que acompanha os sujeitos antunianos ao longo de suas enunciações fragmentárias.

A imagem desse objeto sobre a geladeira irá retornar repetidas vezes, reafirmando o mesmo movimento de repetição compulsiva que estrutura muitos dos textos antunianos, sempre como um índice dessa "afetividade imaginada e perdida" que, no entanto, atualiza-se nas rememorações de cada narrador. Esse objeto não surge apenas como uma indicação do caráter simplório de uma "família" humilde da periferia de Lisboa, não é somente um suvenir de mau gosto do qual se pode desfazer a qualquer tempo, mas se revela como de forte significação para esse texto ficcional em razão de seu imenso valor afetivo. $O$ anão da Branca de Neve torna-se mesmo uma espécie de "guardião" dessa "família":

\section{[...] o anão da Branca de}

Neve severo para mim, permanecíamos tardes seguidas sem mais ninguém em casa

- Tomem conta um do outro se me apoderava da tesoura o anão logo - Vê lá 
proibia-me de cortar vestidos, provar as embalagens de remédio, fazer um lago na banheira

- Livra-te

se dependesse dele não deixava a Gabriela, estou a vê-lo connosco a reprovar-me

- Tantas asneiras Paulo (ANTUNES, 2001b, p. 382).

Objetos

domésticos e sua

dinâmica afetiva em narrativas portuguesas contemporâneas

\author{
[...] para o esmagar no lixo \\ - Temos de comprar outro boneco Paulo \\ erguia a tampa do caixote, objetos antigos passavam-lhe na me- \\ mória, arrependia-se, explicava ao anão \\ - Desta vez salvas-te \\ fazia menções de beijá-lo \\ $[\ldots]$ \\ reparava em mim, empoleirava-o no frigorífico (ANTUNES, \\ 2001b, p. 611).
}

A despeito de sua ambivalente função - ao mesmo tempo em que funciona como protetor e guardião do passado, o objeto atesta o apagamento desse tempo -, torna-se impossível desfazer-se do pequeno bibelô e o desgastado anão permanecerá sobre o refrigerador, Judite jamais conseguirá desvencilhar-se dele, assim como Paulo, que o levará consigo em suas rememorações a todos os outros espaços, todas as outras casas que irá ocupar: de todo o seu passado "em família", no Bico da Areia, restou apenas o pequeno anão, que Paulo desejaria poder fazer desaparecer de sua memória - "mesmo hoje, decorridos vinte anos, se eu pudesse quebrava-o" (ANTUNES, 2001b, p. 54), afirma ele -, mas cuja imagem afetuosa, a proteger a todos numa proteção sem efeito, irá acompanhá-lo insistente e maniacamente. 
Denis Leandro

Francisco

É também a imagem de outro pequeno objeto doméstico, dessa vez uma girafa de plástico dessas que as crianças usam como boia em piscinas, que acompanha Rui. Órfão de pai e mãe, ele é criado com indiferença pela esposa do tio, refugia-se no uso de heroína, torna-se amante de Carlos/Soraia, quinze anos mais velho que ele, e é expulso de casa. Suas recordações de infância serão sempre imagens da impossibilidade: impossibilidade de ter de volta a mãe, morta no parto, ou o pai, morto em um acidente. Acompanhando suas reminiscências está a pequena girafa de plástico, que lhe fazia às vezes de amiga, companheira e confidente: sempre que a esposa do tio o procurava pela casa, encontrava-o "no rebordo da piscina a falar com a girafa" (ANTUNES, 2001b, p. 224). A criança e o objeto são nivelados, igualados em sua solidão e abandono: "deem-lhe a girafa da piscina ou as conversas das criadas para se entreter com os da sua laia" (ANTUNES, 2001b, p. 227), sentencia a tia.

Por meio de um procedimento que tende a aproximar o sujeito do objeto, a criança e a boia de plástico adquirem certa equivalência, indiferenciam-se, de modo semelhante ao que ocorre com o agente de polícia de 0 meu nome é legião - cuja relação com a filha restringe-se à "esperança de um diálogo que não tivemos e continuamos a não ter" (ANTUNES, 2007, p. 34) - e um par de objetos infantis desgastados:

\footnotetext{
[...] e talvez um urso

sem pernas e um Pluto de borracha a que faltava uma orelha, as lágrimas que eu derramaria sobre os bichos se mos mostrassem compadres
}

(ANTUNES, 2007, p. 43)

O agente afirma estar disposto a chorar pelo urso de pelúcia (sem pernas) e pelo Pluto de borracha (a que falta uma orelha), objetos que pertencem à sua filha, mas que ele, no entanto, passa a considerar como seus, tamanha a proximidade que estabelece com eles e a sensação de "compensação" afetiva que esses bonecos kitsch parecem proporcionar aos sujeitos:

\footnotetext{
[...] que sinistro

adoecer ao lado da geringonça que vertia água de um cilindro transparente para copos de plástico que se abandonavam num
} 


\author{
cesto, não quero apagar-me \\ (tenho medo) \\ a assistir às borbulhas subindo à tona enquanto o copo se enche, \\ quero o meu urso sem pernas, o meu Pluto \\ (não sou a minha filha nem nunca tive bonecos, a emoção da \\ morte enganou-me, tive uma ambulância sem rodas com a qual \\ brincava de barriga no chão (ANTUNES, 2007, p. 47, grifos meus).
}

Outra ocorrência dessa aproximação afetiva entre sujeito e objeto pode ser encontrada em Eu hei-de amar uma pedra, no paralelismo que se instaura entre a senhora amante do Pimpolho e a bailarina enferrujada que enfeitava, no passado, a mesa de sua casa. Esse objeto é tão significativo que o próprio protagonista assume sua incapacidade de esquecer-se dele: "conte-me, quanto pesa uma bailarina que não para de me girar na memória" (ANTUNES, 2004, p. 90). Como os demais objetos kitsch, a bailarina que segue girando repetidamente na memória do narrador está também um pouco desgastada - "o mecanismo, com o tempo, um engasgo enferrujado" (ANTUNES, 2004, p. 73) - e sua depauperação ressoa o desgaste físico e emocional desses sujeitos que passaram a vida sem poder efetivar o afeto que nutriam um pelo outro:

\footnotetext{
o médico para mim

- Podemos melhorá-lo se controlarmos os diabetes

a bailarina torta que rodava aos soluços, o vagão de paris e o meu pai a desdenhar-me

- Trambolho

a bailarina imobilizava-se com os cotovelos erguidos, de lado para mim, tu igualmente de lado para mim a mentires-me

- Não me vou embora não chore (ANTUNES, 2004, p. 215).
}

Objetos

domésticos e sua dinâmica afetiva em narrativas portuguesas contemporâneas

Durante cinquenta e dois anos, esse homem, agora casado, encontra-se às quartas-feiras, num quarto de hospedaria no bairro da Graça, com a mulher que amara na juventude e que julgava ter morrido em um sanatório em Coimbra. Quando essa relação impossível é definitivamente barrada pela morte do Pimpolho na mesma hospedaria onde ele e a senhora se reuniam, a amante passa a mimetizar os movimentos da bailarina, em uma espécie de devir que transforma sujeito e objeto em um só: 
Denis Leandro

Francisco o senhor que depois de o levarem da hospedaria da Graça não tornei a

(se depois de o levarem da hospedaria da Graça eu pudesse) o senhor que depois de o levarem da hospedaria da Graça não tornei a ver, no mês passado aluguei um quarto sozinha, os três degraus da entrada impossíveis de subir, um dos rapazes de cabeleira postiça deu-me corda, ajudou-me, um impulso, outro impulso, um rodopio penoso, o rapaz de cabeleira postiça a segurar-me o sovaco

- Empenou tiazinha?

(se lhe pedisse

- Dê-me corda de novo

compreender-me-ia?)

$[\ldots]$

(...) se conseguisse romper a almofada da hospedaria da Graça, romper-me antes que a corda acabe, a musiquinha calada (ANTUNES, 2004, p. 605-606, 608).

Já a pequena girafa de plástico de Que farei quando tudo arde?, semelhantemente ao anão da Branca de Neve, assume um papel protetor para com aqueles que não têm com quem contar: a pequena boia é vista como uma potencial ameaça contra aqueles que destratam Rui, e a tia, por vezes, recua em sua violência contra a criança que invadira sua casa lembrando-lhe a todo instante o que ela, estéril, jamais poderia ter:

[quem narra é a tia de Rui]

sempre que não se trancava no quarto, o Rui entretido com os limões e a girafa, chegava à piscina capaz de bater-lhe vai-te embora desta casa ninguém te quer aqui, o meu marido calado, a girafa calada, ainda receei que a girafa

- Não o atazane senhora mas limitou-se a emagrecer num assobiozinho de vento transformando-se num trapo que o jardineiro recolheu da água juntamente com as folhas (ANTUNES, 2001b, p. 230-231).

$\mathrm{Na}$ ausência de afeto humano, os objetos, mesmo o mais extravagante deles, como um anão de geladeira, ou o mais medíocre, como uma 
girafa inflável, ocupam para os sujeitos o lugar desse outro ausente que nunca responde às demandas afetivas e de atenção das personagens. Quando a tia de Rui

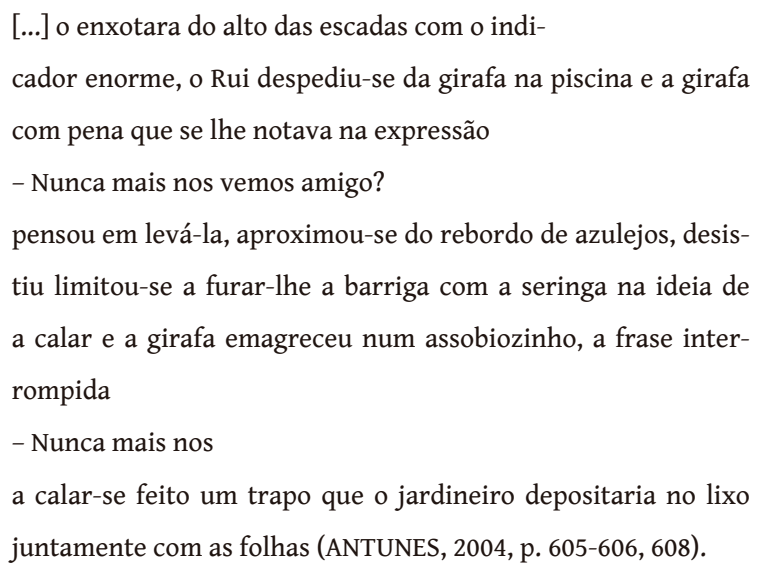

No universo ficcional antuniano, nesse mundo de órfãos irredimidos, elegem-se objetos inanimados e se lhes confere vida própria na tentativa de amenizar o sentimento de orfandade; esse procedimento, no entanto, em lugar de dirimir essa sensação de abandono vivenciada por esses sujeitos e percebida pelo leitor, só faz exacerbá-la ainda mais na medida em que revela a dimensão miseravelmente humana da solidão que envolve as existências esvaziadas de cada personagem. Como Paulo desejaria fazer com seu anão perseguidor, também Rui intenta livrar-se de sua companheira de infância, mas o pequeno "mamífero de plástico", ainda que vertido num trapo, acompanha-o, fantasmaticamente, segundo a rememoração obsessiva do narrador Paulo.

Ao narrar a história de Rui, Paulo ainda tenta salvar-lhe o brinquedo infantil na esperança de, assim, salvar o próprio Rui, salvar sua infância destroçada por mortes e maus tratos, sua vida adulta destruída pelo consumo de heroína e pela solidão: "se eu pudesse colava um adesivo no orifício, soprava o bicho e empoleirava-o na carreta por cima das flores" (ANTUNES, 2001b, p. 220), lamenta ele. Em sua derradeira aparição, a pequena girafa de plástico parece estar à espera de Rui, que não mais voltará, talvez já morto, no hospital, ao lado de Carlos, talvez já morto na areia da praia da Fonte da Telha, onde parece ter se suicidado, quem sabe se à espera de sua única amiga, seu único afeto correspondido, uma pequena girafa deixada para trás: 
[...] a bóia de uma girafa na piscina e eu

a tranquilizá-la

- O Rui está a chegar acalma-te

enquanto ela se me esvaziava nas mãos num assobiozinho de vento

(ANTUNES, 2001b, p. 237).

Vê-se que a textualidade antuniana manifesta sempre uma iro-

Denis Leandro

Francisco nia algo terna em relação aos sujeitos, a suas casas e a seus objetos domésticos. A reflexão aqui desenvolvida acerca desses objetos ficcionais que povoam as casas antunianas não pretende inquiri-los segundo a sua função, mas segundo os processos pelos quais os sujeitos entram em contato com eles e a partir das relações que resultam desse contato ${ }^{2}$, ou seja, pretende analisar o seu potencial mobilizador de afetos. Esses objetos não são nunca destacados nessa ficção por seu aspecto de "novidade" ou "sofisticação", mas por sua aparência desgastada ou kitsch, sempre algo fraturada, em consonância com a existência fragilizada dos seus proprietários. 0 mobiliário - aí compreendidos os objetos e utensílios domésticos - é, como bem lembra Jean Baudrillard, uma espécie de "personificação" das relações humanas:

os móveis e os objetos existem aí primeiro para personificar as relações humanas, povoar o espaço que dividem entre si e possuir uma alma. A dimensão real em que vivem é prisioneira da dimensão moral que têm que significar. Possuem eles tão pouca autonomia neste espaço quanto os diversos membros da família na sociedade. Seres e objetos estão aliás ligados, extraindo os objetos de tal concluio uma densidade, um valor afetivo que se convencionou chamar sua "presença”. Aquilo que faz a profundidade das casas da infância, sua pregnância na lembrança, é evidentemente esta estrutura complexa de interioridade onde os objetos despenteiam diante de nossos olhos os limites de uma configuração simbólica chamada residência [...]. Antropomórficos, estes deuses domésticos, que são os objetos, se fazem, encarnando no espaço os laços afetivos da permanência do grupo,

2 Jacques Rancière irá lembrar a "grande regra freudiana", segundo a qual não existem "detalhes" desprezíveis para corroborar a sua afirmação de que "tudo fala" e que isso significa "dizer também que as hierarquias da ordem representativa foram abolidas" (RANCIÈRE, 2009, p. 36). 
docemente imortais até que uma geração moderna os afaste ou os disperse ou às vezes os reinstaure em uma atualidade nostálgica de velhos objetos (BAUDRILLARD, 2004, p. 22).

A análise de Baudrillard ressalta a força desses "deuses domésticos" cujo caráter simbiótico liga-os irremediavelmente ao grupo por meio das relações afetivas que com eles estabelecem os moradores da casa. Os objetos de Baudrillard são, no entanto, predominantemente dóceis e inofensivos, receptivos e benfazejos, enquanto que na complexa textualidade antuniana esses objetos engendram ao menos duas " "relações morais" primordiais e distintas: i. companhia/evasão/substituição (no passado rememorado, como parte de um mecanismo compensador da falta de afeto e de partilha humanos); e ii. nostalgia/lembrança

Objetos domésticos e sua dinâmica afetiva em narrativas portuguesas contemporâneas (no presente da enunciação, como índice ou vestígio do passado). Em qualquer dos casos, a relação é sempre desigual e o sujeito é sempre "menor" que o objeto, que ou é suficientemente "afetivo" para assumir o lugar do outro (1 $1^{a}$ relação moral) ou se afigurar como um totem do passado ( $2^{\mathrm{a}}$ relação moral), como o fazem o anão da Branca de Neve e a girafa de plástico de Que farei quando tudo arde?.

\section{Considerações finais}

Lobo Antunes afirmou em entrevista que seu livro Que cavalos são aqueles que fazem sombra no mar? teve como gênese - como parece ser procedimento recorrente do autor - um verso escutado de uma senhora: “Como esta casa deve ser triste às três horas da tarde" (ANTUNES, 2009, p. 13). Esse livro abre-se com a descrição de uma prática a que a avó da personagem era submetida na infância:

\footnotetext{
em pequena a minha avó acompanhava a minha bisavó de visita a senhoras que moravam em andares antigos na parte antiga de Lisboa, salas e corredores numa penumbra perpétua onde as pratas e as loiças a seguiam e a minha avó com dez ou onze anos a pensar

- Como esta casa deve ser triste às três horas da tarde porque era nas salas, nos corredores e nos esconsos também,
}

3 Há, ainda, uma terceira relação moral não analisada neste artigo: iii. "pequeno diabo" (no presente da enunciação, como mais um dos elementos que colaboram para tornar "infernal" o cotidiano das personagens, ao mesmo tempo em que fornecem uma amostragem dessas penosas existências). 
com pantufas e vassouras, que chovia no inverno, não lá fora e não chuva tão pouco, uma surpresa nas coisas a condoer-se da gente [...] (ANTUNES, 2009, p. 13).

Para além da tristeza que a narradora antevê naqueles espaços que parecem esquecidos, são as pratas, as loiças e os objetos atulhados que se destacam nessa casa. 0 objeto apresenta certa propriedade de remeter ao passado, condensá-lo e fazê-lo estancar - mesmo que precariamente - como fazem com o fluxo de água os gravetos e as folhas

Denis Leandro

Francisco que se acumulam na superfície de um rio. Assim, essas pequenas "coisas" que exibem surpresa em relação aos sujeitos podem desempenhar uma função bem específica, ainda que nem sempre facilmente percebida: elas pretendem "congelar" o tempo, assim como os pequenos fatos que o cronista registra ou a clássica madeleine proustiana. Como dirá Baudrillard, "não se trata, é claro, do tempo real, são os signos, ou indícios culturais do tempo, que são retomados no objeto antigo" (BAUDRILLARD, 2004, p. 82). Entretanto, o objeto antigo teorizado por Baudrillard é um objeto mitológico, irradiador de forças agregadoras e afirmativas; a exigência à qual ele responde

é a de um ser definitivo, completo. 0 tempo do objeto mitológico é o perfeito: ocorre no presente como se tivesse ocorrido outrora e por isso mesmo acha-se fundado sobre si, "autêntico". o objeto antigo é sempre, no sentido exato do termo, um "retrato de família". Existe sob a forma concreta de um objeto, a imemorialização de um ser precedente - processo que equivale, na ordem imaginária, a uma elisão do tempo. É isto que evidentemente falta aos objetos funcionais, que existem somente na atualidade, no indicativo, no imperativo prático, esgotando-se no seu uso sem ter tido lugar outrora e que, se asseguram mais ou menos bem o meio ambiente no espaço, não o asseguram no tempo. 0 objeto funcional é eficaz, o mitológico, perfeito. É o evento completo que ele significa, o nascimento. Não sou aquele que atualmente é, isto seria a angústia, sou aquele que foi, segundo o fio de um nascimento inverso do qual este objeto é para mim o signo e que do presente mergulha no tempo: regressão. 0 objeto antigo dá-se portanto como mito de origem (BAUDRILLARD, 2004, p. 83-84). 
Ora, o único "retrato de família" que os objetos alocados na ficção antuniana podem fornecer é um retrato apagado ou estilhaçado, já que a "família" nesses textos será sempre uma "família" desagregada. A textualidade antuniana exibe essas moradias propensas à acumulação dessas pequenas "tralhas" - "tesouros sem valor, rinocerontes, tigres e bules" (ANTUNES, 2001a, p. 193), mas esses objetos não têm aqui a força mitológica de "anular o tempo" tornando-o homogêneo e "bloqueando" a sua ação dissipadora, antes, eles consubstanciam a ambivalência da perda e da permanência do passado e de seus afetos, o desejo de uma "origem" e a constatação da sua evasão.

Essa segunda forma de atuação desses objetos domésticos (índice ou vestígio do passado) adquire especial relevância: uma vez que a ficção antuniana procede sempre por movimentos de rememoração, esses

Objetos domésticos e sua dinâmica afetiva em narrativas portuguesas contemporâneas objetos-vestígios demonstram a simbiose entre forma e conteúdo, entre o modo de narrar e a "coisa" narrada - o que parece fundamental para a compreensão desses textos ficcionais -, já que o próprio objeto faz-se movimento do presente em direção ao passado para nele projetar a falta e a solidão do sujeito.

Nas narrativas aqui revisitadas, conforme se viu, o objeto doméstico não assegura, no presente da enunciação, nenhuma "plenitude" advinda de um tempo anterior, antes, esse objeto assinala a compulsão de um sujeito que não consegue se desvencilhar do passado, preso que está à armadilha de uma repetição maníaca. A privação de afeto a que os sujeitos antunianos estão irremediavelmente submetidos dá-se a ver, em negativo, no excesso de afetividade conferida aos seus objetos domésticos, que são, assim, convertidos em "objetos de estima", os quais não se dobram à hierarquização tradicional "animado > inanimado", expondo, dessa forma, uma lógica afetiva que irmana sujeitos e seus objetos.

\section{Referências}

ANTUNES, António Lobo. Exortação aos crocodilos. Rio de Janeiro: Rocco, 2001a.

Que farei quando tudo arde? Lisboa: Dom Quixote, $2001 \mathrm{~b}$.

Eu hei-de amar uma pedra. Lisboa: Dom Quixote, 2004. 
. O meu nome é legião. 3. ed. Lisboa: Dom Quixote, 2007.

Que cavalos são aqueles que fazem sombra no mar?. Lisboa: Dom Quixote, 2009.

BACHELARD, Gaston. A poética do espaço. Traduzido por Antonio de Pádua Danesi. São Paulo: Martins Fontes, 1993. (Coleção Tópicos).

BAUDRILLARD, Jean. 0 sistema dos objetos. Traduzido por Zulmira

Denis Leandro

Francisco Ribeiro Tavares. São Paulo: Perspectiva, 2004. (Coleção Debates. 70).

DELEUZE, Gilles; GUATTARI, Félix. 14.1440: o liso e o estriado. In: Mil platôs: capitalismo e esquizofrenia, vol. 5. Traduzido por Peter Pál Pelbart e Janice Caiafa. São Paulo: Ed. 34, 1997, p. 179-214. (Coleção TRANS).

GAGNEBIN, Jeanne Marie. Walter Benjamin ou a história aberta. In:__. Magia e técnica, arte e política: ensaios sobre literatura e história da cultura. Traduzido por Sergio Paulo Rouanet. 7. ed. São Paulo: Brasiliense, 1994, p. 7-19. (Obras Escolhidas. Vol. 1).

MOLES, Abraham Antoine. 0 kitsch: a arte da felicidade. Traduzido por Sergio Miceli. São Paulo: Perspectiva, 1972. (Coleção Debates. 68).

RANCIÈRE, Jacques. 0 inconsciente estético. Traduzido por Mônica Costa Netto. São Paulo: Ed. 34, 2009.

Recebido em fevereiro de 2018

Aceito em abril de 2018 